
processing*

\title{
1.1 Abstract
}

Litchi is a significant cash crop in Thailand, but marketing is constrained by the perishable nature of the fruit. Drying can extend the shelf life of the fruit; however, in Thailand drying technology is still in its early stages of development. With the aim of improving locally available small-scale drying equipment, the performance of a litchi batch-dryer by a farmers' cooperative near Chiang Mai was studied. Drying conditions, energy consumption and product quality were monitored over three trials. Energy performance was analysed using instantaneous indices, leading to suggestions for possible design-modifications. About $29.8 \%$ of the heat input was used for moisture evaporation, $38.4 \%$ was lost via unsaturated exhaust air and $17.6 \%$ was lost to the ambient environment. An optimum air flow rate, one that minimises exhaust heat losses without increasing the drying time, was calculated. Temperature and air flow within the drying chamber varied, resulting in a nonuniform batch. To improve performance, a new design for the drying chamber air inlet is recommended.

\subsection{Introduction}

Litchi (Litchi chinensis Sonn.) is a tree indigenous to the sub-tropics of southern China (Tindall, 1994). About 95\% of total litchi production is located in Southeast Asia (Huang et al., 2005) and the fruit's sales make a significant contribution to the economies of the producing countries (Ghosh, 2001). Litchis are of significant importance for the Thai economy (Subhadrabandhu \& Yapwattanaphun, 2001); however, market expansion is constrained by the perishable nature of the fruit. After harvest, litchis have a shelf life of 3 to 5 days. At $2-5{ }^{\circ} \mathrm{C}$ fruits can be stored for about 20 days, but deteriorate rapidly after returning to ambient conditions (Jiang \& $\mathrm{Li}, 2003$ ). About $80 \%$ of the litchi producing areas in Thailand are concentrated in mountainous regions of the northern provinces (Anupunt \& Sukhvibul, 2005), where the majority of growers are smallholders (Subhadrabandhu, 1992). During the last 15 years, unstable farm-gate prices and insufficient access to markets have limited profits for these farmers. As a consequence,

\footnotetext{
*Precoppe M; Nagle M; Janjai S; Mahayothee B; Müller J (2011). Analysis of dryer performance for the improvement of small-scale litchi processing. International Journal of Food Science \& Technology, 46 (3), $561-569$.
} 
litchi orchards have been substituted by seasonal field crops, increasing erosion, pesticide use and water demands (Schreinemachers et al., 2009). Small-scale local production of dried litchis by farmer cooperatives is a promising solution for the litchi growers. Such a practice extends the litchi's shelf life significantly (Agarwal \& Nath, 1990), decouples producers from the unstable fresh market, eliminates the middlemen from the value chain and keeps the value added activity within rural areas (Boeer \& Schipmann, 2008). However, in northern Thailand, small-scale drying technology is still in the early stages of development (Nagle et al., 2008). Different convection dryer models have been used, but regardless of the drying equipment selected, small-scale producers face difficulties in achieving uniform batches (Precoppe et al., 2008). This creates an obstacle to the expansion of on-farm processing, because uniform quality of the dried product is essential for commercialisation (Bena \& Fuller, 2002). Additionally, the rising fuel costs represent a serious threat to the level of profitability of the litchi drying activity. Because of the initial high moisture content of the fruit and its strong water bonding forces, drying litchi is a particular energy-intensive activity (Achariyaviriya \& Puttakarn, 2003).

The performance of drying equipment is often described using indices such as the drying rate, energy requirements and specific heat consumption of the dryer. Such values are useful when comparing different dryers, but give no idea about changes in energy utilisation during the drying process and; therefore, have limited application when seeking improvements to dryer designs (Kudra, 2004; Men'shutina et al., 2005). In contrast, instantaneous indices, calculated from time-distributed parameters, take into account temporal variations and can thus lead to design optimisation (Kudra, 2004; Strumiłło et al., 2007). With the aim of proposing dryer-design modifications that will improve the energy performance and quality of locally available small-scale drying equipment, the performance of a litchi batch dryer, used by a farmers' cooperative in Thailand, was studied. Performance indices were calculated and plotted against time. An analysis of those instantaneous indices was used to devise and propose possible modifications to the dryer

\subsection{Material and methods}

\subsubsection{Drying procedure}

Three trials were conducted at a farmers' cooperative located in the village of Mae Sa Mai in Chiang Mai Province, Thailand, and a locally available convection batch dryer was used. This direct-heat dryer was $1.75 \mathrm{~m}$ tall, $1.22 \mathrm{~m}$ wide and $1.22 \mathrm{~m}$ deep, and the walls 
were made of $1.5 \mathrm{~mm}$ steel sheet metal. Seventeen square trays sized $0.63 \mathrm{~m}^{2}$ each, with metal sides and a metallic mesh at the base, were stacked $9 \mathrm{~cm}$ apart in a tray rack. The tray rack was mounted on a carrousel and turned on its vertical axis, making the trays rotate at six revolutions per minute. The system was powered by a $0.990 \mathrm{~kW}$ electric motor. The temperature of the air in the drying chamber was maintained by a gas burner controlled by a thermostat and fuelled by liquefied petroleum gas (LPG). From the burner to the chamber, air flowed through a $4 \mathrm{~m}$ long air duct adjacent to the dryer. In this duct, the heated air mixed with a portion of the exhaust air (the recirculation function). Air flow was induced by a radial blade blower powered by a second $0.990 \mathrm{~kW}$ electric motor. At the end of the duct, air entered the drying chamber through two longitudinal openings at the near right-hand corner of the dryer which ran the entire height of the chamber. The blower produced an air mass flow rate of $62.7 \mathrm{~g} \mathrm{~s}^{-1}$ resulting on an air velocity at the drying chamber, near those openings, of $3.9 \mathrm{~m} \mathrm{~s}^{-1}$.

The trials followed the usual drying operation of the facility, using high grade ripe litchis (var. 'hong-huay') grown in the surrounding Mae Sa watershed. Fruits were harvested 2 days before starting the trial and kept at an ambient temperature. The fruits were punched at the stem for deseeding then peeled by hand. The peeled fruits were then immersed in a $0.03 \%(\mathrm{w} / \mathrm{v})$ citric acid solution, followed by immersion in $0.05 \%(\mathrm{w} / \mathrm{v})$ potassium metabisulphite solution for $7 \mathrm{~min}$ at room temperature. After that, the fruits were placed on the trays in a single layer and with a loading density of $9.60 \pm 0.41 \mathrm{~kg} \mathrm{~m}^{-2}$. The initial $X$ of the sample varied between $86 \%$ and $88 \%$ wet basis (wb). The drying process followed a stepwise temperature regime: the first step lasted for $2 \mathrm{~h}$ and the thermostat was adjusted at $70{ }^{\circ} \mathrm{C}$, the second step lasted $6 \mathrm{~h}$ with thermostat at $65^{\circ} \mathrm{C}$ and the third step, at $60{ }^{\circ} \mathrm{C}$, lasted for $6 \mathrm{~h}$ or until the facility operators considered the fruit to be fully dried. To improve the uniformity of the final product, the trays were removed at various intervals during the last step and in accordance with the fruits' drying stage.

\subsubsection{Measurements}

The temperature $\left(T_{\text {tray }}\right)$ and relative humidity $\left(\varphi_{\text {tray }}\right)$ of the drying air were recorded using 25 autonomous, miniature thermometer-hygrometer data loggers (TRH-logger) (SugarCube Clima; Meilhaus Electronic, Puchheim, Germany) which were placed in quintuplets over dryer trays 3, 5, 7, 9 and 11 (the top tray was tray 1). The TRH-loggers were aligned from the centre to the corner of the tray; $100 \mathrm{~mm}$ apart. The ambient air 
temperature $\left(T_{\mathrm{amb}}\right)$ and ambient relative humidity $\left(\varphi_{\mathrm{amb}}\right)$ were also recorded using a TRHlogger. The exhaust air temperature $\left(T_{\text {out }}\right)$, relative humidity $\left(\varphi_{\text {out }}\right)$ and velocity ( $\left.v_{\text {out }}\right)$ were measured by placing a TRH-logger and a vane anemometer (MiniAir 6 Mini; Schiltknecht, Gossau, Switzerland) at the dryer outlet, and for calculation of the air flow, a $350 \mathrm{~mm}$ long $5 "$ plastic tube was used as an air duct at the dryer's air outlet. The same anemometer was also used to measure the velocity of the mixed air ( $\left.v_{\text {duct }}\right)$ moving through the duct feeding air into the drying chamber. In addition, the temperature ( $\left.T_{\text {duct }}\right)$ and relative humidity of the mixed air ( $\varphi$ duct $)$ were recorded using a HygroClip, a humidity-temperature probe (SC05; Rotronic, Bassersdorf, Switzerland), which was connected along with the anemometer to a data acquisition unit (HygroLab 2; Rotronic, Bassersdorf, Switzerland). The data acquisition unit was attached to a notebook to record the data, and all the data measurements were synchronised and logged at 30-s intervals. Electricity consumption was measured using an analogue kilowatt-hour metre. The initial and final mass of the LPG cylinder as well as initial and final mass of the loaded trays were obtained using an industrial digital balance $( \pm 0.01 \mathrm{~kg})$. Fig 1-1 shows, schematically, the location of the measurements and in parenthesis, the location of the calculated parameters.

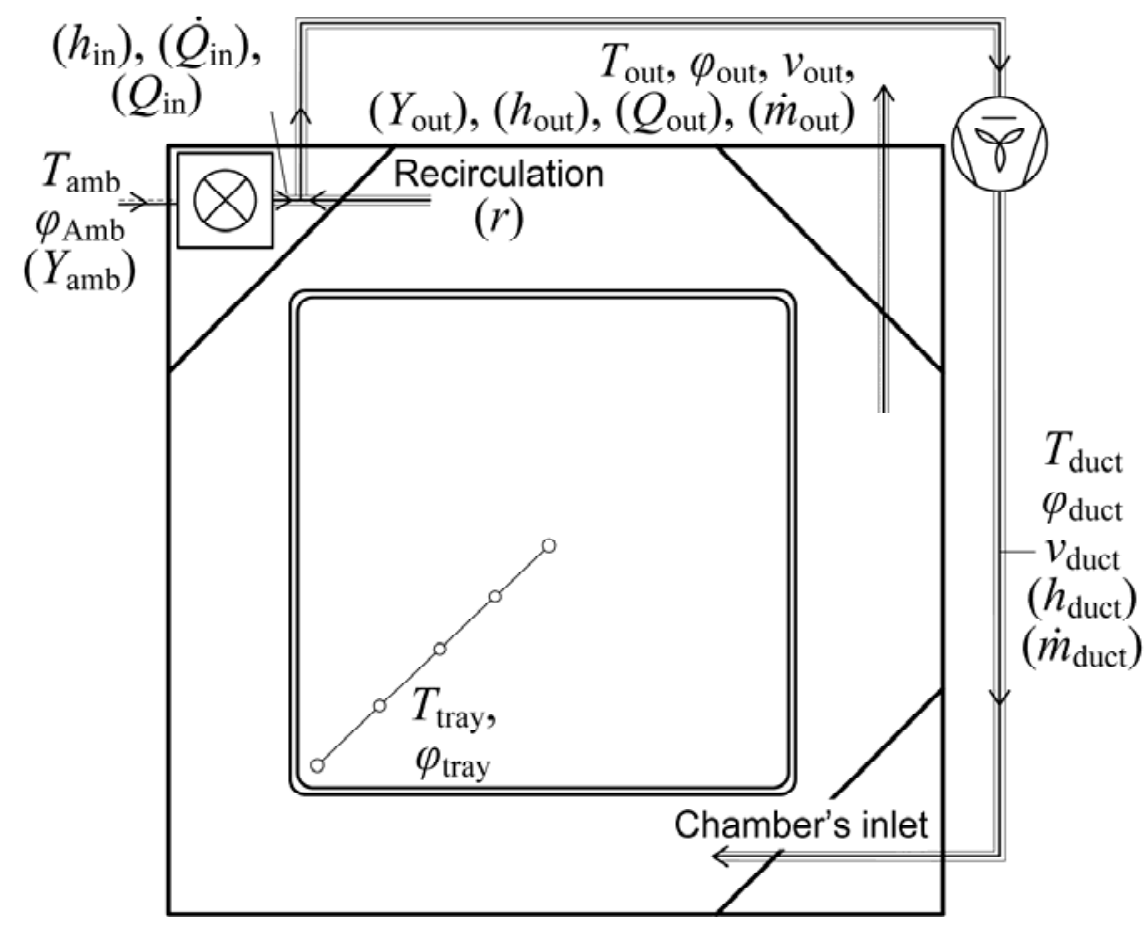

Fig 1-1. Top cross-sectional view of the dyer with measurement locations for air temperature $(T)$, relative humidity $(\varphi)$ and air velocity $(v)$, as well as the locations used for calculating absolute humidity $(Y)$, enthalpy $(h)$, power $(\dot{Q})$, heat $(Q)$, air mass flow $(\dot{m})$ and the proportion of recirculated air $(r)$. 
Air velocity values above the trays were obtained using a cup anemometer (f.555.1.12, Schiltknecht, Gossau, Switzerland). Those measurements were performed without fruit and at ambient temperature. Tray rotation was suspended for the readings and measurements were made near the chamber air inlet, with three repetitions.

\subsubsection{Energy analysis}

To analyse the energy performance of the dryer, cumulative and instantaneous indices were used, as suggested by Kudra (2004). Indices were adapted from the International Standard for Determination of Drying Performance (ISO, 1997). The drying rate $\left(\dot{n}_{\mathrm{w}}\right)$ was obtained by dividing the evaporation rate $(\dot{w})$ by the dry mass of the litchi used for the trial $(m \mathrm{dm})$. The evaporation rate was calculated based on the absolute humidity of the exhaust air ( $\left.Y_{\text {out }}\right)$ taking into account the absolute humidity of the ambient air $\left(Y_{\mathrm{amb}}\right)$ and the air mass flow rate $\left(\dot{m}_{\text {out }}\right)$, as shown in Eq. $0-1$ :

$$
\dot{n}_{\mathrm{w}}=\frac{\dot{w}}{m_{\mathrm{dm}}}=\frac{\left(Y_{\mathrm{out}}-Y_{\mathrm{amb}}\right) \dot{m}_{\mathrm{out}}}{m_{\mathrm{dm}}}
$$

The heat input $\left(Q_{\text {in }}\right)$ was obtained from the thermal power input $\left(\dot{Q}_{\text {in }}\right)$ over time and the thermal power input was calculated based on the enthalpy of the heated air ( $\left.h_{\text {in }}\right)$ and the air mass flow rate (Eq. 0-2):

$$
Q_{\text {in }}=\dot{Q}_{\text {in }} \cdot \Delta t=h_{\text {in }} \cdot \dot{m}_{\text {out }} \cdot \Delta t
$$

The enthalpy of the heated air was calculated based on the enthalpy of the mixed air at the duct $\left(h_{\text {duct }}\right)$, the enthalpy of the exhaust air $\left(h_{\text {out }}\right)$ and the proportion of recirculated air $(r)$, as shown in Eq. 0-3:

$$
h_{\text {in }}=\frac{h_{\text {duct }}-r \cdot h_{\text {out }}}{1-r}
$$

The proportion of recirculated air was obtained by dividing the mass flow rate of the recovered exhaust air $\left(\dot{m}_{\mathrm{r}}\right)$ by the mass flow rate of the mixed air $\left(\dot{m}_{\text {duct }}\right)$, as shown in Eq. $0-4$. The recovered mass flow rate was obtained by measuring the difference between the mass flow of the mixed air at the duct and the air mass flow at the dryer outlet.

$$
r=\frac{\dot{m}_{\mathrm{r}}}{\dot{m}_{\mathrm{duct}}}=\frac{\dot{m}_{\mathrm{duct}}-\dot{m}_{\mathrm{out}}}{\dot{m}_{\mathrm{duct}}}
$$


To determine the heat used to evaporate a unit mass of water, specific heat consumption $(q \mathrm{c})$ was obtained by dividing the heat input by the evaporation mass $\left(m_{\mathrm{w}}\right)$, as shown in Eq. 0-5. The evaporation mass was calculated from the evaporation rate.

$$
q_{\mathrm{C}}=\frac{Q_{\mathrm{in}}}{m_{\mathrm{w}}}
$$

To determine the heat used to produce a unit mass of dried litchi, the specific heat utilisation $\left(q_{\mathrm{U}}\right)$ was calculated by dividing the heat input by the mass of dried litchi obtained $\left(m_{\mathrm{f}}\right)$, as shown in Eq. 0-6:

$$
q_{\mathrm{U}}=\frac{Q_{\mathrm{in}}}{m_{\mathrm{f}}}
$$

Energy efficiency $(\eta)$ was obtained by calculating the ratio between the heat used for moisture evaporation $\left(Q_{\mathrm{w}}\right)$ and the heat input. The heat used for moisture evaporation was calculated from the evaporation mass and the litchis' isosteric heat of sorption $\left(E_{\mathrm{st}}\right)$, as shown in Eq. 0-7. The isosteric heat of sorption was used instead of the latent heat of vaporisation to take account of water-bonding forces, as suggested by Kudra (2009).

$$
\eta=\frac{m_{\mathrm{w}} \cdot \lambda}{Q_{\mathrm{in}}}=\frac{m_{\mathrm{w}} \cdot E_{\mathrm{st}}}{Q_{\mathrm{in}}}=\frac{Q_{\mathrm{w}}}{Q_{\mathrm{in}}}
$$

Litchi isosteric heat of sorption was entered as a function of moisture content $(X)$ in dry basis, as modelled by Janjai et al. (2010), as shown in Eq. 0-8:

$$
E_{\mathrm{st}}=\left(50.892 e^{-0.023 X}\right) 55.5087
$$

Heat losses via the unsaturated exhaust air $\left(Q_{\mathrm{L}, \mathrm{out}}\right)$ were quantified by calculating the difference between the actual exhaust heat $\left(Q_{\text {out }}\right)$ and the theoretical exhaust heat in saturated exhaust air $\left(Q_{\text {out }}^{*}\right)$, as shown on Eq. $0-9$. The exhaust heat was calculated from the enthalpy of the exhaust air. The exhaust heat in saturated exhaust air was calculated based on the minimum air mass flow $\left(\dot{m}_{\text {out }}^{*}\right)$; enough to hold the evaporation rate.

$$
Q_{\mathrm{L}, \mathrm{out}}=Q_{\mathrm{out}}-Q_{\mathrm{out}}^{*}=\left(h_{\mathrm{out}} \cdot \dot{m}_{\mathrm{out}} \cdot \Delta t\right)-\left(h_{\mathrm{out}} \cdot \dot{m}_{\mathrm{out}}^{*} \cdot \Delta t\right)
$$

The minimum air mass flow was calculated based on the evaporation rate and the absolute humidity of the saturated exhaust air $\left(Y_{\text {out }}^{*}\right)$, taking the ambient absolute humidity into account, as shown in Eq. 0-10: 


$$
\dot{m}_{\text {out }}^{*}=\frac{\dot{w}}{Y_{\text {out }}^{*}-Y_{\text {amb }}}
$$

Total heat losses to the ambient air $\left(Q_{\mathrm{L}, \mathrm{amb}}\right)$ were calculated based on the difference between input heat and exhaust heat $\left(Q_{\text {out }}\right)$, as shown in Eq. $0-11$.

$$
Q_{\mathrm{L}, \mathrm{amb}}=Q_{\mathrm{in}}-Q_{\text {out }}
$$

Unaccounted losses $\left(Q_{\mathrm{L}, \mathrm{n}}\right)$ were calculated, as shown in Eq. 0-12:

$$
Q_{\mathrm{L}, \mathrm{n}}=Q_{\mathrm{in}}-\left(Q_{\mathrm{w}}+Q_{\mathrm{L}, \mathrm{amb}}+Q_{\mathrm{L}, \mathrm{out}}\right)
$$

\subsubsection{Quality analysis}

To verify the homogeneity of the drying conditions in the chamber, air velocity and drying air temperature were analysed. The values for air velocity above the trays were evaluated with a one-way analysis of the variance, using the least significant difference for a means comparison at a probability level of 5\%. Procedures were performed using SAS 9.2 (SAS Institute Inc., Cary, USA). Temperature uniformity was analysed by plotting a map of the air temperature at trays 3, 7 and 11 during the second drying step. Interpolation was used to estimate the values between measuring points. Additionally, to verify variations during the drying process, temperatures at the corner and centre of these same trays were plotted against drying time.

During the trials, fruits from trays 5, 9 and 13 were sampled at $2 \pm 0.5 \mathrm{~h}$ intervals. Samples were evaluated in terms of moisture content $(X)$, water activity $\left(a_{\mathrm{w}}\right)$ and colour. Moisture content was obtained by the static gravimetric method (ASABE, 2008), using a laboratory convection oven (UFB 500; Memmert Co., Schwabach, Germany) at $103{ }^{\circ} \mathrm{C}$, and drying the samples until a constant weight was reached (approximately $72 \mathrm{~h}$ ). Water activity was determined using a water activity metre (AW-DIO; Rotronic, Bassersdorf, Switzerland). Readings were performed with finely chopped samples at $25^{\circ} \mathrm{C}$, using a thermostatic chamber. Flesh colour was evaluated for three fruits per sample using a colorimeter (CR300; Minolta Inc., Osaka, Japan). The instrument was set in the CIELAB colour space and at a $\mathrm{D}_{65}$ illumination. Colour values were expressed as $L^{*}$ (lightness), $a^{*}$ (red/green) and $b^{*}$ (yellow/blue). Each fruit was scanned at two different locations, and both the $a^{*}$ and $b^{*}$ values were then converted to a hue angle $(H)$. 


\subsection{Results and discussion}

\subsubsection{Energy analysis}

Table 1-1 shows the obtained cumulative energy performance indices. Total heat input was 717.3 MJ, of which 228.9 MJ was used for evaporation. The electrical energy consumption required to power the dryer's two electrical motors added up to $43.0 \mathrm{MJ}$, representing $5.7 \%$ of the total energy input. For each kilogram of water evaporated, 12.1 MJ of heat was required, and to produce $15.4 \mathrm{~kg}$ of dried litchi, $15.9 \mathrm{~kg}$ of LPG was required. Specific heat utilisation was very similar to that obtained by Tippayawong et al. (2009), who studied another type of convection batch dryer used in Thailand. Although their experiments were carried out with peeled longan (Dimocarpus longan Lour.), the results can be compared because litchi and longan have a similar biological structure and their isosteric heats of sorption have the same pattern of variation in terms of $X$ (Janjai et al., 2009; Janjai et al., 2010).

Table 1-1. Overall means and standard deviation (SD) of the performance indices for the convection dryer across all three trials

\begin{tabular}{lllll}
\hline Performance Indices & Unit & Mean & \pm SD \\
\hline Mass of fresh litchi used for trials $\left(m_{\mathrm{i}}\right)$ & $\mathrm{kg}$ & 102.87 & \pm 4.34 \\
Mass of dried litchi obtained $\left(m_{\mathrm{f}}\right)$ & $\mathrm{kg}$ & 15.40 & \pm 0.96 \\
Evaporation mass $\left(m_{\mathrm{w}}\right)$ & $\mathrm{kg}$ & 87.47 & \pm 3.72 \\
Fuel consumption $\left(m_{\mathrm{LPG}}\right)$ & $\mathrm{kg}$ & 15.94 & \pm 0.74 \\
Duration of trials $(t)$ & hours & 15.67 & \pm 0.14 \\
Thermal power input $\left(\dot{Q}_{\mathrm{in}}\right)$ & $\mathrm{kW}$ & 12.52 & \pm 1.07 \\
Electric energy consumption $(E)$ & $\mathrm{MJ}$ & 42.98 & \pm 1.48 \\
Drying rate $\left(\dot{n}_{\mathrm{w}}\right)$ & $\mathrm{kg} \mathrm{kg}^{-1} \mathrm{~h}^{-1}$ & 0.412 & \pm 0.006 \\
Specific heat consumption $(q \mathrm{C})$ & $\mathrm{MJ} \mathrm{kg}^{-1}$ & 12.13 & \pm 0.75 \\
Specific heat utilization $\left(q_{\mathrm{U}}\right)$ & $\mathrm{MJ} \mathrm{kg}^{-1}$ & 45.63 & \pm 4.24 \\
Heat input used for moisture evaporation & $\%$ & 29.80 & \pm 1.54 \\
Heat input losses via exhaust air & $\%$ & 38.38 & \pm 2.98 \\
Heat input losses to the ambient air & $\%$ & 17.57 & \pm 2.43 \\
Heat input unaccounted losses & $\%$ & 14.79 & \pm 1.33 \\
\hline
\end{tabular}

Fig 1-2 shows how the instantaneous indices varied during the drying process. The initial $X$ of the fruits was $6.70 \mathrm{~kg} \mathrm{~kg}^{-1}$, which steadily decreased over time. Kuhn (1962) obtained similar drying curves for litchi, but the resulting drying time was longer as a lower temperature was applied. Energy performance was analysed until the product reached a $X$ 
of $0.17 \mathrm{~kg} \mathrm{~kg}^{-1}$. Litchi drying rate is mainly controlled by the product $X$ (Janjai et al., 2010) and the drying air temperature (Zhao et al., 1999). Fig 1-2 shows that the drying rate was highest at the beginning of the drying process $\left(0.982 \mathrm{~kg} \mathrm{~kg}^{-1} \mathrm{~h}^{-1}\right)$, and declined as drying proceeded, reaching its minimum $\left(0.115 \mathrm{~kg} \mathrm{~kg}^{-1} \mathrm{~h}^{-1}\right)$ at the end. Litchi membranes display a strong resistance to water movement (Zhao et al., 1999; Janjai et al., 2010); therefore, drying occurred at the falling rate period. Other researchers (Achariyaviriya et al., 2001; Achariyaviriya \& Puttakarn, 2003; Janjai et al., 2011), have also observed declining constant drying rate over the entire period of the litchi drying process.

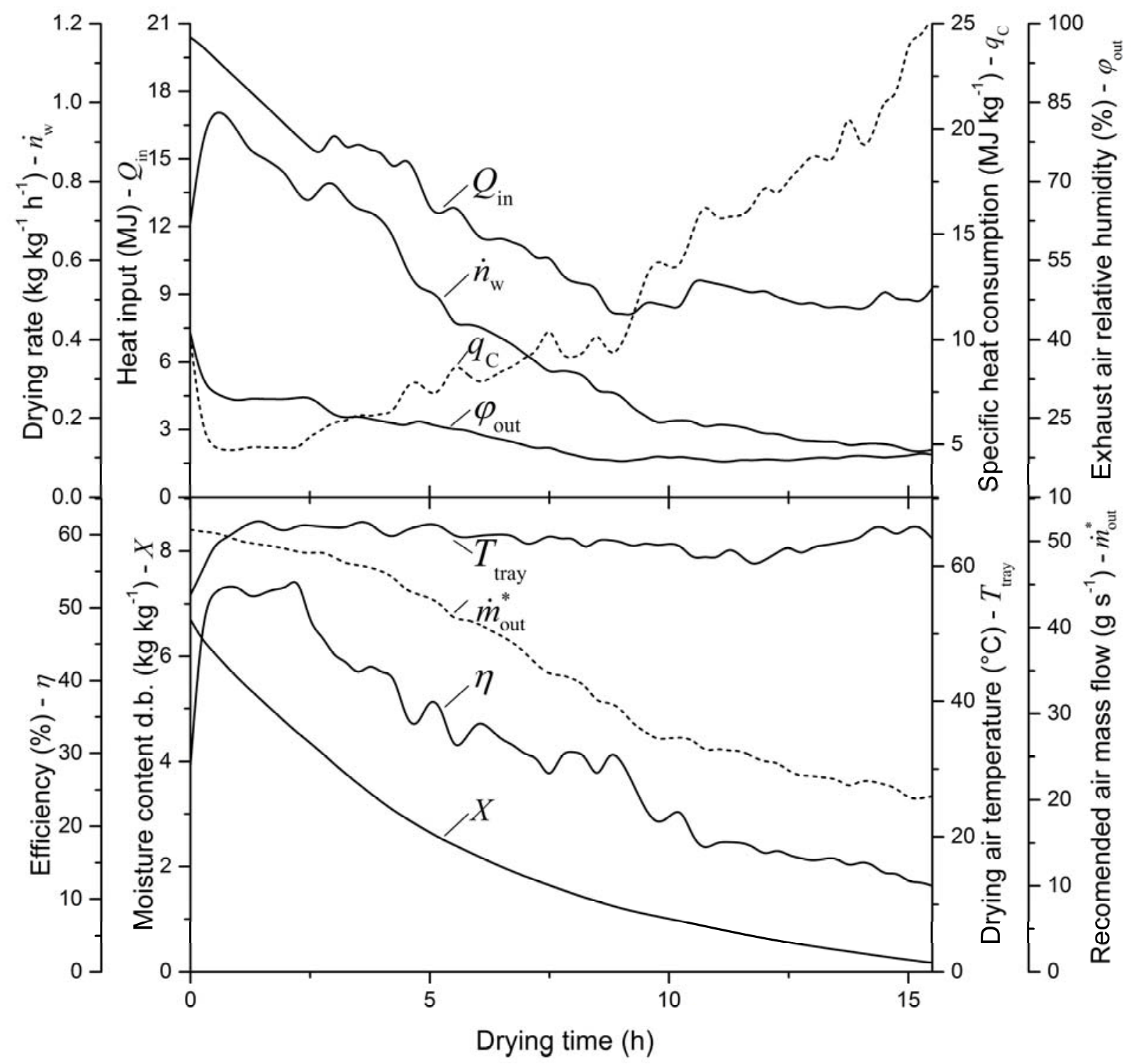

Fig 1-2. Mean values for the heat input $\left(Q_{\text {in }}\right)$, drying rate $\left(\dot{n}_{\mathrm{w}}\right)$, specific heat consumption $\left(q_{\mathrm{C}}\right)$, relative humidity of the exhaust air $\left(\varphi_{\text {out }}\right)$, drying air temperature $\left(T_{\text {tray }}\right)$, optimum air mass flow $\left(\dot{m}_{\text {out }}^{*}\right)$, energy efficiency $(\eta)$ and moisture content dry basis $(X)$, during the drying process. 
As a result of the stepwise adjustment of the thermostat, power input was highest $(22.7 \mathrm{~kW})$ at the beginning of the process and lowest $(9.5 \mathrm{~kW})$ towards the end. However, Fig 1-2 reveals that the reduction in heat input was not as severe as the reduction in the drying rate, and consequently, specific heat consumption increased as drying proceeded, being at a minimum $\left(4.72 \mathrm{MJ} \mathrm{kg}^{-1}\right)$ during the beginning of the process and reaching a maximum towards the end $\left(25.02 \mathrm{MJ} \mathrm{kg}^{-1}\right)$. This observed growing specific heat consumption can also be attributed to the hygroscopic water bonding forced, particularly strong at products with high sugar content - which is the case for litchi (Mahayothee et al., 2009; Reichel et al., 2010). The average energy efficiency of the dryer was $29.8 \%$ - very similar to the figure obtained by Tippayawong et al. (2009). Fig 1-2 shows that in the first $2.5 \mathrm{~h}$ of the drying process, energy efficiency was at its highest, reaching $54.7 \%$, but that after the product $X$ fell below $4.5 \mathrm{~kg} \mathrm{~kg}^{-1}$, efficiency declined, reaching a minimum of $11.8 \%$ at the end of the drying process.

Fig 1-2 shows that the temperature and relative humidity of the exhaust air were highest $\left(62.1{ }^{\circ} \mathrm{C}\right.$ and $\left.41.3 \%\right)$ at the beginning of the drying process. Exhaust air temperature remained mostly constant over time (min. temp. $58.4{ }^{\circ} \mathrm{C}$ ), but relative humidity gradually decreased, reaching its lowest value of $16.7 \%$ at the end of the process; therefore, the absolute humidity of the exhaust air varied from 76.63 to $25.12 \mathrm{~g} \mathrm{~kg}^{-1}$.

Fig 1-3 shows changes in the percentage of heat input used for moisture evaporation and the percentage of heat input lost. A total of $247.2 \mathrm{MJ}$ was lost via unsaturated exhaust air, this being the main component of the heat loss. It was at a minimum at the beginning $(11.3 \%)$, and reached a maximum at the end of the drying process $(56.52 \%)$. In addition, a total of 101.2 MJ was lost to the ambient air, mostly through convective and radiation losses, as the metallic walls and ducts of the dryer were not insulated. Fig 1-3 shows that throughout the drying process, the percentage of heat input lost to the ambient air remained mostly constant. During the three trials, the average ambient temperature was $28.0 \pm 0.7^{\circ} \mathrm{C}$, and average ambient absolute humidity was $17.5 \pm 0.4 \mathrm{~g} \mathrm{~kg}^{-1}$. 


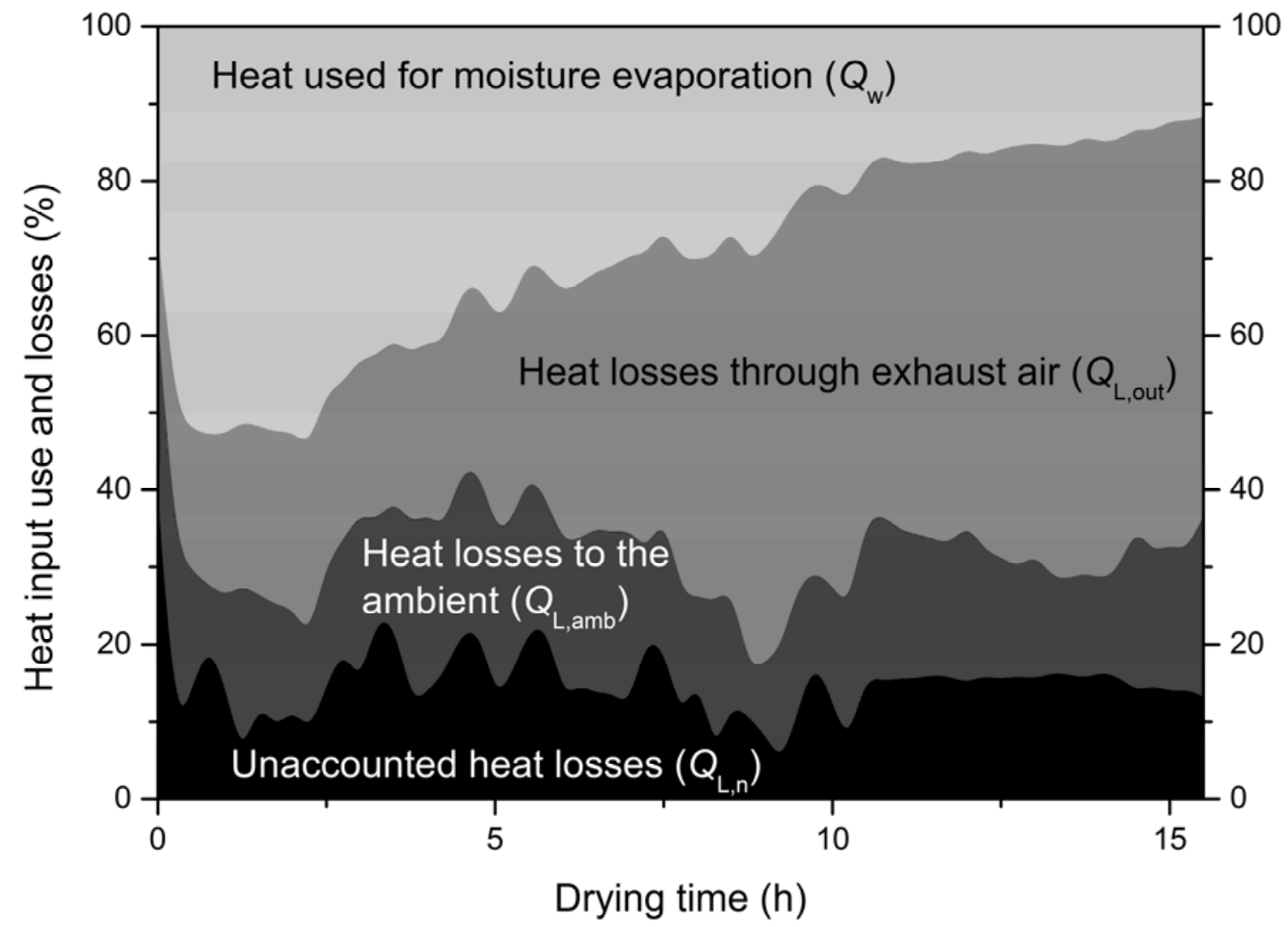

Fig 1-3. Mean values for the heat input percentage allocation used for moisture evaporation $\left(Q_{\mathrm{w}}\right)$, losses by exhaust air $\left(Q_{\mathrm{L}, \mathrm{out}}\right)$ and losses to the ambient air $\left(Q_{\mathrm{L}, \mathrm{amb}}\right)$ during the drying process.

An analysis of these instantaneous indices could be used to guide dryer design modifications. Fig 1-2 shows the air mass flow that would minimise exhaust heat losses, which decreases with drying time; starting at $51.38 \mathrm{~g} \mathrm{~s}^{-1}$ and reaching its lowest value of $20.07 \mathrm{~g} \mathrm{~s}^{-1}$ at the end of the drying process. This air mass flow would increase saturation levels within the exhaust air, but without jeopardising the drying forces. Achariyaviriya et al. (2001) observed that a reduction in air flow can significantly decrease the specific heat consumption of litchi drying; therefore, it could be expected that a gradual reduction in air flow would counteract the observed increments in specific heat consumption.

Another way to minimise exhaust heat losses, as an alternative to reducing air flow, would be to gradually increase the proportion of recirculated air, which, in the current dryers, runs at $44.3 \%$. Air recirculation is also one of the main factors to influence the energy performance of convection dryers (Achariyaviriya et al., 2000; Baker, 2005). This alternative would dispense with the need to install a frequency-converter to control the blower speed. The recirculation rate could be simply controlled by altering the size of the air outlet; closing it to increase recirculation. Tippayawong et al. (2009) were able to 
significantly improve the energy performance of a convection dryer by applying a recirculation regime that increased from $70 \%$ at the beginning of the process, to $90 \%$ at the end.

In addition, thermal insulation of the walls and ducts of the dryer would help to reduce heat losses to the ambient air and, thus, improve the energy performance. Tippayawong et al. (2009) obtained a significant improvement in efficiency by insulating the walls and ducts of convection dryers, and Nagle et al. (2010) observed that insulation enhances the temperature distribution inside the drying chamber. As a result, this modification could also have a positive impact on product quality.

\subsubsection{Quality analysis}

Fig 1-4 shows the average air velocity at the dryer trays. Fig 1-5a shows the temperatures across trays 3, 7 and 11 during the second step of the drying process, and Fig 1-5b shows how the temperature differences between the corner and centre of those trays varied during the process. Fig 1-6 shows changes in moisture content, water activity and colour of the products for trays 5, 9 and 13 over the drying period.

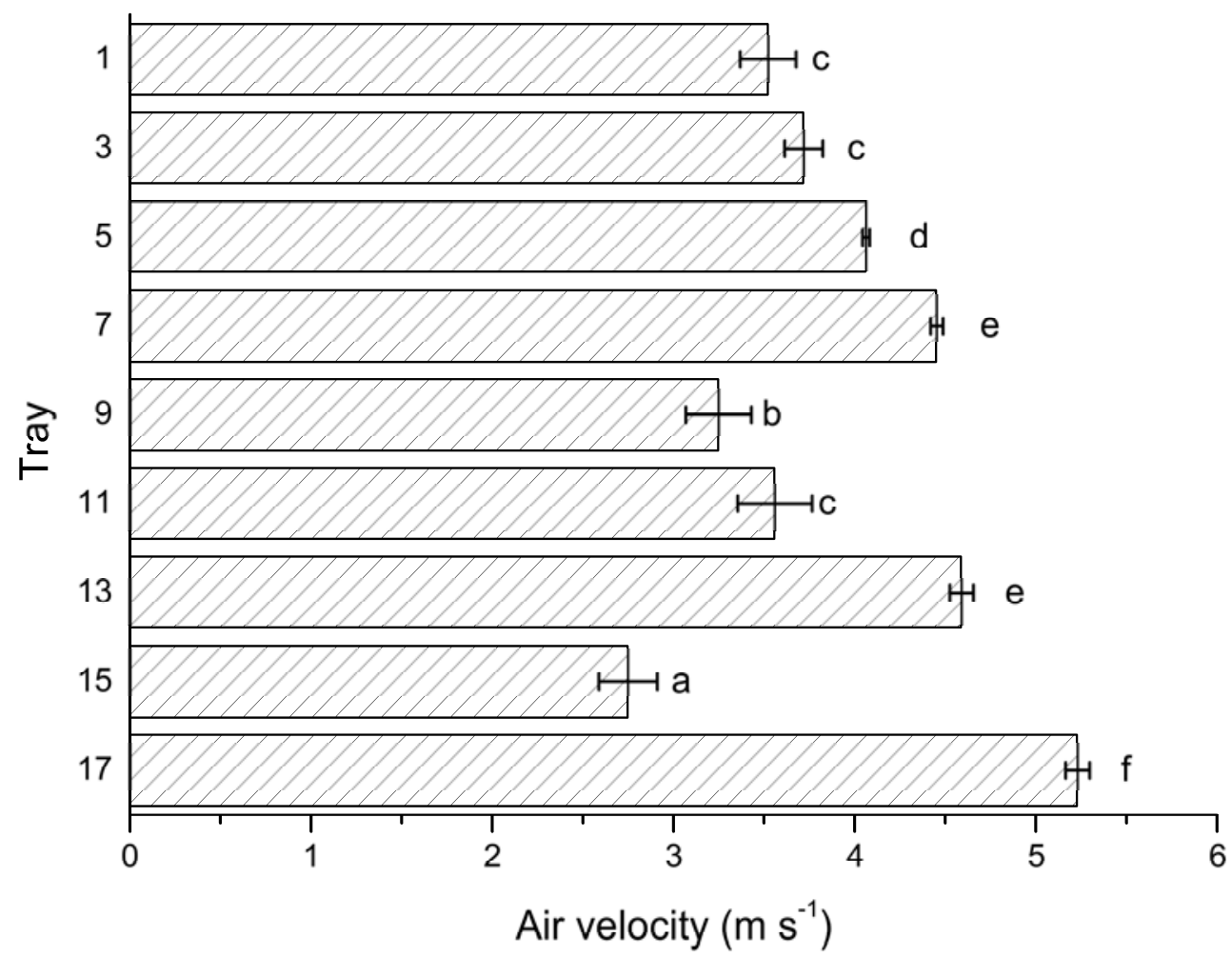

Fig 1-4. Mean values for the air velocity above the trays of the dryers (top = tray 1 ). Error bars indicate standard deviation and letters significant differences $(P<0.05)$. 

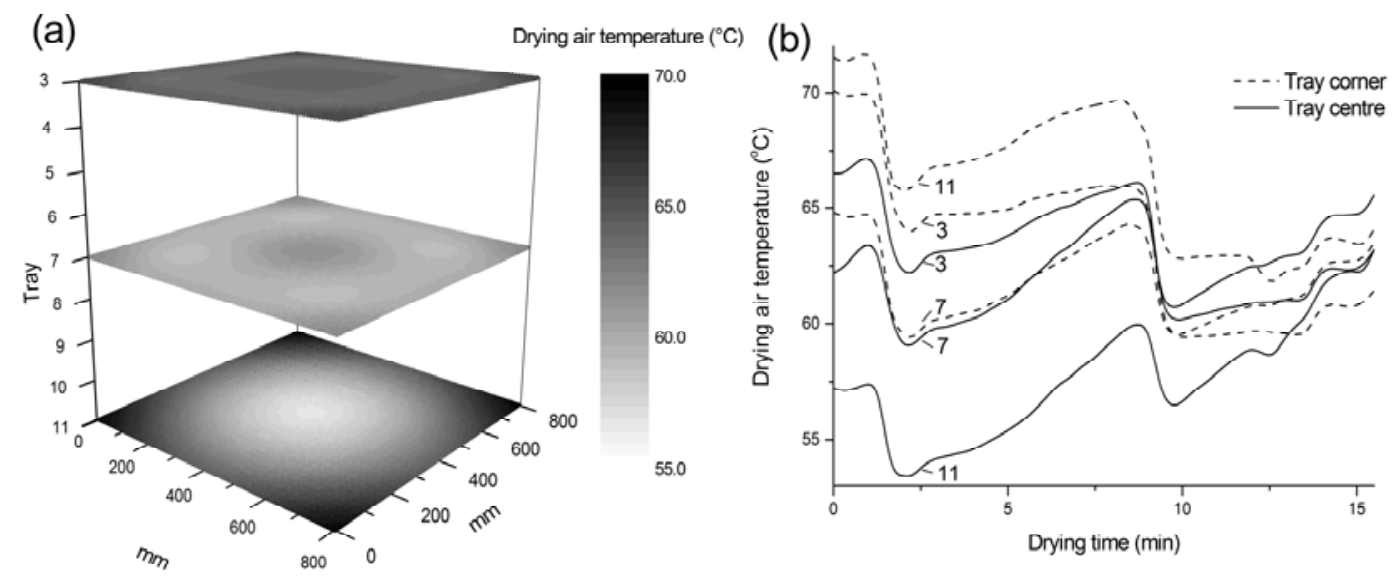

Fig 1-5. (a) Drying air temperatures for trays 3, 7 and 11 (top = tray 1), during the second drying step, and (b) Drying air temperatures at the corner and at the centre of trays 3, 7 and 11 during the drying process.

Significant differences in air velocity above the trays were observed (Fig 1-4), and temperature distribution in the drying chamber also varied between trays (vertically) and across trays (horizontally). Whereas the magnitude of the temperature disparities decreased as drying proceeded (Fig 1-5b), moisture content, water activity and colour were nevertheless affected by the non-uniform air flow and temperature (Fig 1-6). From Fig $1-5 b$, it is possible to observe the effect that the stepwise adjustment of the thermostat created on the chamber's temperature. This is not visible in Fig 1-2, because of chamber temperature heterogeneity, as it shows the average of 25 different measuring points.

Fig 1-6 shows that the mean initial $X$ of the samples was $86.9 \pm 1.1 \%$ wb, which then steadily decreased over the course of the drying process. The samples on tray 9 of the dryer did not reach the recommended $X$ for safe, long-term storage, which should be less than $30 \% \mathrm{wb}$ (Kuhn, 1962). Regarding water activity, the recommended upper limit of $a_{\mathrm{w}} \leq 0.6$ required for storability (Beuchat, 1981), was not achieved by the samples on trays 5 and 9 . The fresh litchi samples had an average lightness value of $69.6 \pm 2.6$ and an average hue angle of $141.4 \pm 6.9^{\circ}$, but during the drying process the fruit became darker and the hue angle decreased. The final colour of the dried litchi was a light golden-brown, lighter than the $L^{*}$ values reported by Pott et al. (2000) and more yellow than $H$ values reported by Mahayothee et al. (2009). Consumer preferences in terms of the colour of dried litchi have not yet been determined, but for longan, golden-yellow is the preferred colour (Achariyaviriya et al., 2001; Tippayawong et al., 2009). 


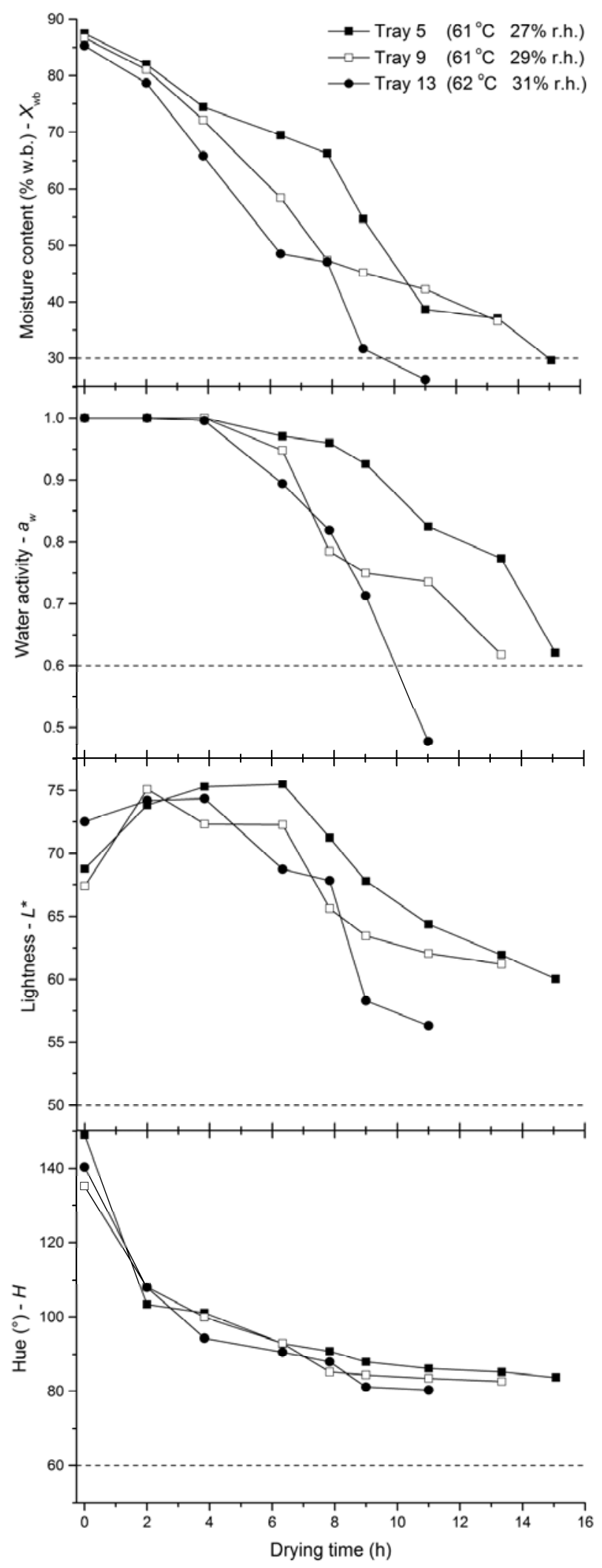

Fig 1-6. Moisture content $(X)$, water activity and colour changes in the litchi fruits during the drying process. Values in parentheses are average temperatures and relative humidity of the drying air. Dashed lines represent reference values from Kuhn (1962) for X, Beuchat (1981) for water activity, Pott et al. (2000) for lightness and Mahayothee et al. (2009) for hue angle. 
Poor air-flow distribution and consequently poor temperature homogeneity in the drying chamber, is a common problem for the locally available convection dryers used in Thailand (Nagle et al., 2008; Tippayawong et al., 2009; Nagle et al., 2010). For peeled litchis, the drying temperature has a strong effect on drying rates (Janjai et al., 2011) and product colour (Achariyaviriya \& Puttakarn, 2003), and as a consequence, the batches obtained in this study were not homogenous. Redesigning the air inlet of the drying chamber to achieve a homogenous vertical and horizontal air flow, could improve temperature distribution, and; thus, product quality.

\subsection{Conclusions}

Analysis of the performance indices demonstrated that the main heat losses occurred via exhaust air. These losses could be mitigated by decreasing the airflow as drying proceeds, or increasing the proportion of air recirculated. The time-based indices indicate that a gradual reduction in the airflow, or a stepwise increment of the recirculation rate, would not jeopardise evaporative capacity and thus would not extend drying times. Heterogeneous air flow produced non-uniform temperatures between and across trays, affecting product quality. Therefore, a more homogenous batch may be achieved by redesigning the drying chamber air inlet to obtain an equal air flow between and across the trays. In addition, insulation of the dryer may help reduce losses to the ambient air and also improve heat distribution within the drying chamber. Overall, it is believed that these simple modifications will improve the energy and quality performance of the dryer, without impacting adversely on manufacturing requirements or equipment price.

\subsection{Acknowledgments}

This study was conducted as part of an international program named "Sustainable Land Use and Rural Development in the Mountainous Regions of Southeast Asia” (SFB 564), funded by Deutsche Forschungsgemeinschaft (DFG), and was co-funded by the National Research Council of Thailand (NRCT). The research was also made possible through financial support from the Eiselen Foundation Ulm and the Deutscher Akademischer Austausch Dienst (DAAD). Gratitude should be expressed to the Hmong Mae Sa Valley Cooperative. 


\subsection{References}

Achariyaviriya A; Soponronnarit S; Tiansuwan J (2000). Mathematical simulation of longan fruit drying. Kasetsart Journal - Natural Science, 34, 300-307

Achariyaviriya A; Soponronnarit S; Tiansuwan J (2001). Study of longan flesh drying. Drying Technology, 19 (9), 2315-2329

Achariyaviriya S; Puttakarn B (2003). A mathematical model of effective moisture diffusivity for lychee drying. Proceedings of the International Conference on Crop Harvesting and Processing. Louisvilley, KY: ASAE

Agarwal N; Nath N (1990). Effect of pretreatments on quality characteristics and water activity of air-dried litchis (Litchi chinensis Sonn.) cv. Rose Scented. Food/Nahrung, 34 (3), 255-263

Anupunt P; Sukhvibul N (2005). Lychee and longan production in Thailand. Acta Horticulturae (ISHS), 665, 53-60

ASABE (2008). ASAE S358.2 DEC1988 (R2008) Moisture measurements - Forages. In: ASABE Standards 2008: Standards Engineering Practices Data (edited by American Society of Agricultural and Biological Engineers), pp 670-672, St. Joseph, MO: ASABE

Baker C G J (2005). Energy efficient dryer operation - An update on developments. Drying Technology, 23 (9-11), 2071-2087

Bena B; Fuller R J (2002). Natural convection solar dryer with biomass back-up heater. Solar Energy, 72 (1), 75-83

Beuchat L R (1981). Microbial stability as affected by water activity. Cereal Foods World, $26(7), 345-349$

Boeer T; Schipmann C (2008). Assessment of different value-chain upgrading strategies for litchi farmers in northern upland parts in Thailand. Proceedings Tropentag 2008. Stuttgart, Germany

Ghosh S P (2001). World trade in litchi: Past, present and future. Acta Horticulturae (ISHS), 558, 23-30

Huang X; Subhadrabandhu S; Mitra S; Ben-Aire R; Stern R (2005). Origin, history, production and processing. In: Litchi and Longan: Botany, Production and Uses (edited by C. Menzel and G. Maite), pp 1-24, Wallingford, UK: CABI Publishing

ISO (1997). International Standard 11520-1:1997 Agricultural grain drier - Determination of drying performance. International Organization of Standardization, Geneva, Switzerland

Janjai S; Intawee P; Tohsing K; Mahayothee B; Bala B K; Ashraf M A; Müller J (2009). Neural network modeling of sorption isotherms of longan (Dimocarpus longan Lour.). Computers and Electronics in Agriculture, 66 (2), 209-214

Janjai S; Lamlert N; Tohsing K; Mahayothee B; Bala B K; Müller J (2010). Measurement and modeling of moisture sorption isotherm of litchi (Litchi chinensis Sonn.). International Journal of Food Properties, 13 (2), 251-260 
Janjai S; Precoppe M; Lamlert N; Mahayothee B; Bala B K; Nagle M; Müller J (2011). Thin-layer drying of litchi (Litchi chinensis Sonn.). Food and Bioproducts Processing, 89 (3), 194-201

Jiang Y M; Li Y B (2003). Effects of low-temperature acclimation on browning of litchi fruit in relation to shelf life. Journal of Horticultural Science and Biotechnology, 78 (4), 437-440

Kudra T (2004). Energy aspects in drying. Drying Technology, 22 (5), 917-932

Kudra T (2009). Energy aspect in food dehydration. In: Advances in Food Dehydration (edited by C. Ratti), pp 423-445, Boca Raton, FL: CRC Press

Kuhn G (1962). Dehydration studies of lychee fruit. Florida Agricultural Experiment Stations Journal Series, 1581, 273-277

Mahayothee B; Udomkun P; Nagle M; Haewsungcharoen M; Janjai S; Mueller J (2009). Effects of pretreatments on colour alterations of litchi during drying and storage. European Food Research and Technology, 229 (2), 329-337

Men'shutina N V; Gordienko M G; Voinovskii A A; Kudra T (2005). Dynamic criteria for evaluating the energy consumption efficiency of drying equipment. Theoretical Foundations of Chemical Engineering, 39 (2), 158-162

Nagle M; González-Azcárraga J C; Phupaichitkun S; Mahayothee B; Haewsungcharern M; Janjai S; Leis H; Müller J (2008). Effects of operating practices on performance of a fixed-bed convection dryer and quality of dried longan. International Journal of Food Science and Technology, 43 (11), 1979-1987

Nagle M; González Azcárraga J C; Mahayothee B; Haewsungcharern M; Janjai S; Müller J (2010). Improved quality and energy performance of a fixed-bed longan dryer by thermodynamic modifications. Journal of Food Engineering, 99 (3), 392-399

Pott I; Bühle M; Mühlbauer W; Wiriyacharee P (2000). Drying lychee fruits (Litchi chinensis Sonn.) for preserving quality and vitamin C. Proceedings Tropentag 2000. Stuttgart, Germany

Precoppe M; Nagle M; Piepho H-P; Mahayothee B; Janjai S; Haewsungcharern M; Müller J (2008). Analysis of current practices of litchi drying in small scale industries in northern Thailand. Proceedings Tropentag 2008. Stuttgart, Germany

Reichel M; Carle R; Sruamsiri P; Neidhart S (2010). Influence of harvest maturity on quality and shelf-life of litchi fruit (Litchi chinensis Sonn.). Postharvest Biology and Technology, 57 (3), 162-175

Schreinemachers P; Berger T; Sirijinda A; Praneetvatakul S (2009). The diffusion of greenhouse agriculture in northern Thailand: Combining econometrics and agent-based modeling. Canadian Journal of Agricultural Economics, 57 (4), 513-536

Strumilło C; Jones P L; Zyłla R (2007). Energy aspects in drying. In: Handbook of Industrial Drying (edited by A. S. Mujumdar), pp 1075-1101, Boca Raton, FL: Taylor \& Francis 
Subhadrabandhu S (1992). Status of the tropical fruit industry in Thailand. Acta Horticulturae (ISHS), 292, 13-24

Subhadrabandhu S; Yapwattanaphun C (2001). Lychee and longan production in Thailand. Acta Horticulturae (ISHS), 558, 49-57

Tindall H D (1994). Sapindaceous fruits: botany and horticulture. In: Horticultural Reviews (edited by J. Janick), pp 143-196, New York, NY: John Wiley \& Sons, Inc.

Tippayawong N; Tantakitti C; Thavornun S; Peerawanitkul V (2009). Energy conservation in drying of peeled longan by forced convection and hot air recirculation. Biosystems Engineering, 104 (2), 199-204

Zhao H; Li C; Guan Z (1999). Experimental research on drying characteristics of litchi. Drying Technology, 17 (9), 1915-1925 